\title{
Enhancing Stability and Oxidation Activity of Cytochrome $c$ by Immobilization in the Nanochannels of Mesoporous Aluminosilicates
}

\author{
Chia-Hung Lee, ${ }^{\dagger}$ Jun Lang, ${ }^{*}$ Chun-Wan Yen, ${ }^{\dagger}$ Pei-Chun Shih, ${ }^{\dagger}$ Tien-Sung Lin, ${ }^{*}, *$ and \\ Chung-Yuan Mou*, \\ Department of Chemistry, National Taiwan University, Taipei, Taiwan 106, and Department of Chemistry, \\ Washington University, St. Louis, Missouri 63130 \\ Received: January 31, 2005; In Final Form: April 18, 2005
}

\begin{abstract}
Hydrothermally stable and structrurally ordered mesoporous and microporous aluminosilicates with different pore sizes have been synthesized to immobilize cytochrome $c$ (cyt $c$ ): MAS-9 (pore size $90 \AA$ ), MCM-48-S (27 $\mathrm{A})$, MCM-41-S $(25 \AA)$, and Y zeolites (7.4 $⿱$ A). The amount of cyt $c$ adsorption could be increased by the introduction of aluminum into the framework of pure silica materials. Among these mesoprous silicas (MPS), MAS-9 showed the highest loading capacity due to its large pore size. However, cyt $c$ immobilized in MAS-9 could undergo facile unfolding during hydrothermal treatments. MCM-41-S and MCM-48-S have the pore sizes that match well the size of cyt $c(25 \times 25 \times 37 \AA)$. Hence the adsorbed cyt $c$ in these two medium pore size MPS have the highest hydrothermal stability and overall catalytic activity. On the other hand, the pore size of $\mathrm{NaY}$ zeolite is so small that cyt $c$ is mostly adsorbed only on the outer surface and loses its enzymatic activity rapidly. The improved stability and high catalytic activity of cyt $c$ immobilized in MPS are attributed to the electrostatic attraction between the pore surface and cyt $c$ and the confinement provided by nanochannels. We further observed that cyt $c$ immobilized in MPS exists in both high and low spin states, as inferred from the ESR and UV-vis studies. This is different from the native cyt $c$, which shows primarily the low spin state. The high spin state arises from the replacement of Met-80 ligands of heme Fe (III) by water or silanol group on silica surface, which could open up the heme groove for easy access of oxidants and substrates to iron center and facilitate the catalytic activity. In the catalytic study, MAS-9-cyt $c$ showed the highest specific activity toward the oxidation of polycyclic aromatic hydrocarbons (PAHs), which arises from the fast mass transfer rate of reaction substrate due to its large pore size. For pinacyanol (a hydrophilic substrate), MCM41-S-cyt $c$ and MCM-48-S-cyt $c$ showed higher specific activity than NaY-cyt $c$ and MAS-9-cyt $c$. The result indicated that cyt $c$ embedded in the channels of MCM-41-S and MCM-48-S was protected against unfolding and loss of activity. By increasing the concentration of the spin trapping agent, 5,5-dimethyl-1-pyrroline $\mathrm{N}$-oxide (DMPO) in ESR experiments, we showed that cyt $c$ catalyzes a homolytic cleavage of the $\mathrm{O}-\mathrm{O}$ bond of hydroperoxide and generates a protein cation radical $(g=2.00)$. Possible mechanisms for MPS-cyt $c$ catalytic oxidation of hydroperoxides and PAHs are proposed based on the spectroscopic characterizations of the systems.
\end{abstract}

\section{Introduction}

Cytochrome $c$ (cyt $c$ ) is an intermembrane mitochondrial heme protein. In vivo, electrons are transported from cyt $c$ reductase to cyt $c$ oxidase, followed by reduction of oxygen molecule to water, which provides the driving force for ATP synthesis. ${ }^{1}$ In vitro, cyt $c$ is a good biocatalyst (peroxidase-like) to decompose hydrogen peroxide and organic hydroperoxides. Cyt $c$ has been reported to catalyze the oxidation of a wide variety of organic substrates, including polycyclic aromatic hydrocarbons (PAHs). ${ }^{2-7}$ PAHs have been considered as potential health hazards due to their possible carcinogenic and mutagenic activities. The transformation of PAHs to innocuous compounds has been a subject of extensive research. ${ }^{6}$ However, the transformation of a hydrophobic substrate like PAHs is usually limited by its low water solubility and diffusion rate. Many approaches have been reported to overcome these difficulties: utilization of nontoxic surfactants to enhance the

* Corresponding authors. T.S.L.: Fax 314-935-4481; E-mail lin@wustl.edu; C.Y.M.: Fax +886-2-23660954; E-mail cymou@ntu.edu.tw.

National Taiwan University.

$\doteqdot$ Washington University. transformation of PAHs, ${ }^{8}$ water-miscible organic solvents to solve the solubility problem, ${ }^{9}$ raising temperature to increase the solubility and diffusion rate. Most notably, Vazquez-Duhalt et al. used chemical modification on the heme protein surface with poly(ethylene glycol). ${ }^{10}$ The modified cyt $c$ has cage-like polymer protection and shows good activity at high temperatures. ${ }^{11}$ Site-directed mutagenesis showed that catalytic activity was improved by ten-fold in Gly82:Thr102 variant in comparison with the wild type. ${ }^{10,12}$ A variety of supports have also been used to immobilize cyt $c$ to improve the stability under extreme conditions. ${ }^{2 \mathrm{c}, \mathrm{d}, 7,13-16}$

Mesoporous silica (MPS) has generated vast interest ever since it was synthesized by Beck et al. in $1992 .{ }^{17}$ Stucky et al. used triblock copolymer and developed MPS with large pore size $\left(50-150 \AA\right.$ ) with ordered hexagonal structure. ${ }^{18}$ Because of its large surface area (about $1000 \mathrm{~m}^{2} / \mathrm{g}$ ), highly ordered pore structure, and adjustable pore size (20-400 ̊), MPS has been applied extensively in chemistry and biotechnology. ${ }^{19-22}$ In addition, MPS also provides confined nanospace that could stabilize catalytic centers and enzymes. ${ }^{5,23-30}$ It has been shown that cyt $c$ immobilized in MPS could improve stability and maintain its enzymatic activity for several months. ${ }^{21,23}$ 
Recently, we reported the application of MPS materials to encapsulate a hydroxo-bridged di-nuclear phenanthroline cupric complex to mimic catechol oxidases. ${ }^{20} \mathrm{We}$ found that MPS materials with large pore diameters and accessible surface modification with functional groups and ionic species are good candidates for biomimetic studies of these systems. For testing catalysis of immobilized enzyme or a biomimetic at high temperature, we need mesoporous silica materials of exceptionally high stability. We have developed synthetic strategies to overcome the long-standing problems of poor hydrothermal stability of MCM-41 and difficulties in introducing heteroatom (Al) onto SBA-15. We employed $\beta$-zeolitic nanoclusters as precursors and various surfactants as templates to make mesoporous silica MCM-41-S (S denotes zeolite seed), ${ }^{31} \mathrm{MCM}-48$ $\mathrm{S},{ }^{31}$ and MAS-9. ${ }^{32}$ The zeolitic nanoclusters yield crystal-like structures in the wall of mesopores that are different from the amorphous mesoporous materials prepared by the traditional method. This improves not only the pore quality of the material but also the hydrothermal stability. Its structure remains intact even after 10 days of hydrothermal treatment in boiling water. We have synthesized aluminum substituted MPS with different pore size (25-90 A) and structure (MCM-41-S, MAS-9: 1D hexagonal; MCM-48-S: 3D cubic) to incorporate cyt $c$ with optimal activity and stability. Furthermore, we shall demonstrate that aluminum substituted MPS and cyt $c$ have stronger electrostatic attraction, which yields a higher loading of cyt $c$ in the nanochannels of MPS and inhibits cyt $c$ from leaching during the catalytic process. We employed MPS-cyt $c$ to study their catalytic activities and reaction mechanisms in the cleavage of organic hydroperoxides and the oxidation of PAHs under an extreme condition at $100{ }^{\circ} \mathrm{C}$, where the native cyt $c$ would have lost most of its activity. ${ }^{11}$

\section{Experimental Section}

1. Chemicals. Horse heart cytochrome $c$, 5,5-dimethyl-1pyrroline $\mathrm{N}$-oxide (DMPO), diethylenetriaminepentaacetic acid (DTPA), tert-butyl hydroperoxide (TBHP, 70\%), cumene hydroperoxide (CHP, 80\%), Chelex 100, and fumed silica were all obtained from Sigma Chemical Co. Orange II, hydrogen peroxide $(35 \%)$, pinacyanol chloride, tetraethylammonium hydroxide (TEAOH, 20\% aqueous solution), cetyltrimethylammonium bromide (CTAB), and tetraethyl orthosilicate (TEOS) were all obtained from Acros. Tetrapropylammonium hydroxide (TPAOH, 20\% aqueous solution), pyrene, and anthracene were obtained from Fluka. Pluronic P123 $\left(\mathrm{EO}_{20} \mathrm{PO}_{70} \mathrm{EO}_{20}\right)$ was obtained from Aldrich. $\mathrm{NaAlO}_{2}$ was obtained from Riedel-deHaen.

2. Preparation of Catalysts. Cyt $c$ (isoelectric point, $\mathrm{pI}=$ 9.8) carries positive charges under neutral conditions $(\mathrm{pH}=$ 7.5). By introducing aluminum to the silica framework, we created negative charges on the pore surface, which then attracts the positively charged cyt $c$ to enter the nanochannels of MPS. There are two positively charged regions in cyt $c$ surface that can bind to the negatively charged aluminum sites. One area is the lysine-rich surface (Lys-54, - 55, -72, -73, and His-39), and the other has surface residues of histidine and lysine (His$33,-36$, Lys-22, and -27$){ }^{26}$

(a) Preparation of $M C M-41-S$ and $M C M-48-S$ ( $\mathrm{Si} / \mathrm{Al}=37)$. The $\beta$-zeolite nanocluster was prepared by mixing $\mathrm{NaAlO}_{2}$, $\mathrm{NaOH}$, fumed silica, TEAOH aqueous solution $(20 \%)$ with $\mathrm{H}_{2} \mathrm{O}$ under stirring. The mixture was then hydrothermally treated at $100{ }^{\circ} \mathrm{C}$ for $18 \mathrm{~h}$. The final product was a clear nanoprecursor solution. MCM-48-S was prepared by mixing zeolitic nanocluster solution with CTAB solution and followed by hydro- thermal treatment at $150{ }^{\circ} \mathrm{C}$ for $6-24 \mathrm{~h} .{ }^{31}$ Similarly, MCM41-S was prepared by mixing zeolitic nanocluster solution with $\mathrm{CTAB}$ and followed by hydrothermal treatment for $2-6 \mathrm{~h}$, to which was then added $1.2 \mathrm{M} \mathrm{H}_{2} \mathrm{SO}_{4}$ to adjust $\mathrm{pH}$ to 10 . The mixture was hydrothermally treated again at $100{ }^{\circ} \mathrm{C}$ for 2 days. As-synthesized sample was collected by filtration, dried at 100 ${ }^{\circ} \mathrm{C}$ for $6 \mathrm{~h}$, and calcined at $580{ }^{\circ} \mathrm{C}$ for $6 \mathrm{~h}$ to remove the organic surfactant. The molar ratio of the reactants used in the experiment was $1 \mathrm{NaAlO}_{2}, 37 \mathrm{SiO}_{2}, 1.5-9 \mathrm{NaOH}, 11-22$ TEAOH, $18.3 \mathrm{CTAB}$, and $3000-3500 \mathrm{H}_{2} \mathrm{O} .{ }^{31}$

(b) Synthesis of MAS-9 (Si/Al = 25). Large-pore zeolite seed stabilized MAS- 9 was synthesized by the method as reported by Xiao et al. ${ }^{32}$ The zeolite precursor solution was prepared by mixing $6 \mathrm{~mL}$ of TPAOH $(20-25 \%), 0.12 \mathrm{~g}$ of $\mathrm{NaAlO}_{2}, 5.6$ $\mathrm{mL}$ of TEOS with $12 \mathrm{~mL}$ of $\mathrm{H}_{2} \mathrm{O}$ under stirring. The mixture was hydrothermally treated at $100{ }^{\circ} \mathrm{C}$ for $2-3 \mathrm{~h}$ until it became a clear nanoprecursor solution. $0.8 \mathrm{~g}$ of Pluronic P123 was dissolved in $20 \mathrm{~mL}$ of $\mathrm{H}_{2} \mathrm{O}$ with $5 \mathrm{~mL}$ of $10 \mathrm{M} \mathrm{HCl}$ solution, followed by an addition of $7 \mathrm{~mL}$ of aforementioned nanoprecursors. The mixture was stirred at $40{ }^{\circ} \mathrm{C}$ for $20 \mathrm{~h}$ and then hydrothermally treated at $100{ }^{\circ} \mathrm{C}$ for $36 \mathrm{~h}$. The product was collected by filtration, dried in air, and calcined at $550{ }^{\circ} \mathrm{C}$ for $5 \mathrm{~h}$ to remove the organic template. The molar ratio of the reactants used in the experiment was $1 \mathrm{Al}_{2} \mathrm{O}_{3}, 50 \mathrm{SiO}_{2}, 1 \mathrm{Na}_{2} \mathrm{O}$, 7 (TPA) $)_{2} \mathrm{O}$, and $1800 \mathrm{H}_{2} \mathrm{O}$.

(c) Immobilization of cyt $c$ in MPS. First, $20 \mu \mathrm{M}$ cyt $c$ stock solution was prepared by dissolving $0.067 \mathrm{~g}$ of cyt $c$ in 270 $\mathrm{mL}$ of $0.05 \mathrm{M} \mathrm{KH}_{2} \mathrm{PO}_{4}-\mathrm{NaOH}$ buffer solution $(\mathrm{pH}=7.5)$ under stirring. Then, $0.15 \mathrm{~g}$ of MPS was added into $30 \mathrm{~mL}$ of stock solution under stirring at $4{ }^{\circ} \mathrm{C}$ for $3 \mathrm{~h}$. The MPS-cyt $c$ solids were collected by filtration and dried in vacuum. Cyt $c$ loading was determined by monitoring the change in the strong absorption band at $407 \mathrm{~nm}\left(\epsilon=100000 \mathrm{M}^{-1} \mathrm{~cm}^{-1}\right.$, Soret band).

3. Characterizations. The surface area, pore size, and pore volume were determined by $\mathrm{N}_{2}$ adsorption-desorption isotherms obtained at $77 \mathrm{~K}$ on a Micrometric ASAP 2010 apparatus. The sample was outgassed at $10^{-3}$ Torr and $200{ }^{\circ} \mathrm{C}$ for about $3 \mathrm{~h}$ prior to the adsorption experiment. The pore size distribution curves were obtained from the analysis of the adsorption portion of the isotherms using the BJH (Barrett-Joyner-Halenda) method. The diffuse reflectance UV-vis spectra were measured with a Hitachi U-3010 spectrophotometer. When dealing with solid samples, samples were loaded in a quartz cell and an integrating sphere was included to collect the reflected light. The spectra were collected in $200-800 \mathrm{~nm}$ wavelength range against a standard. The powder X-ray diffraction spectra of these samples are given in the Supporting Information.

ESR spectra were recorded on an X-band ESR spectrometer (Bruker EMX). A flat rectangular quartz sample cell was used to measure the ESR spectra of liquid mixtures. A quartz tubing of $4 \mathrm{~mm}$ OD was used to measure the ESR spectra of solids. The spectrometer was equipped with a variable-temperature setup, which allowed us to perform low-temperature experiments (10 K to room temperature) of solids. Typical spectrometer settings were: (a) For liquid sample: microwave frequency, 9.775 $\mathrm{GHz}$; microwave power, $2 \mathrm{~mW}$; center field, $3480 \mathrm{G}$; sweep width, $100 \mathrm{G}$; time constant, $655.36 \mathrm{~ms}$; modulation amplitude, 1 G. (b) For solid sample: microwave frequency, $9.526 \mathrm{GHz}$; microwave power, $2 \mathrm{~mW}$; center field, $2600 \mathrm{G}$; sweep width, $5000 \mathrm{G}$; time constant, $40.96 \mathrm{~ms}$; modulation amplitude, 5 G.

4. Enzyme Stability and Activity. (a) Hydrothermal Stability. Hydrothermal stability was determined by heating $0.05 \mathrm{~g}$ MPS-cyt $c$ solids in boiling water for 12 and $24 \mathrm{~h}$, then 
TABLE 1: Amount of Cytochrome $c$ Adsorbed, Surface Area, and Pore Volume of the MPS Samples before and after Cytochrome $c$ Adsorption

\begin{tabular}{|c|c|c|c|c|c|c|c|}
\hline sample & $\begin{array}{c}\text { cyt } c \\
\text { adsorbed } \\
(\mu \mathrm{mol} / \mathrm{g})\end{array}$ & $\begin{array}{l}\text { surface area } \\
\left(\mathrm{m}^{2} / \mathrm{g}\right) \\
\text { before cyt } c \\
\text { adsorption }\end{array}$ & $\begin{array}{l}\text { surface area } \\
\left(\mathrm{m}^{2} / \mathrm{g}\right) \\
\text { after cyt } c \\
\text { adsorption }\end{array}$ & $\begin{array}{c}\text { pore size } \\
(\AA)\end{array}$ & $\begin{array}{l}\text { pore volume } \\
\left(\mathrm{cm}^{3} / \mathrm{g}\right) \\
\text { before cyt } c \\
\text { adsorption }\end{array}$ & $\begin{array}{l}\text { pore volume } \\
\left(\mathrm{cm}^{3} / \mathrm{g}\right) \\
\text { after cyt } c \\
\text { adsorption }\end{array}$ & $\begin{array}{c}\text { max. loading } \\
\text { of cyt } c \\
(\mu \mathrm{mol} / \mathrm{g})\end{array}$ \\
\hline $\mathrm{NaY}$ & 0.68 & 810 & 715 & 7.4 & 0.340 & 0.335 & 0.97 \\
\hline MCM-41-S & 3.18 & 845 & 600 & 25 & 0.422 & 0.392 & 6.35 \\
\hline MCM-48-S & 4.35 & 1012 & 787 & 27 & 0.892 & 0.604 & 4.96 \\
\hline MAS-9 & 4.28 & 843 & 554 & 90 & 1.057 & 0.910 & 30.52 \\
\hline
\end{tabular}

measuring its Soret band absorption at $407 \mathrm{~nm}$ to find out its change before and after the hydrothermal treatment. The Soret band of cyt $c$ decreased irreversibly after hydrothermal treatment at $100{ }^{\circ} \mathrm{C}$, indicating the destruction of active sites.

(b) PAH Oxidation. It was reported that the cyt $c / \mathrm{H}_{2} \mathrm{O}_{2}$ system could catalyze the oxidation of pyrene and anthracene to form 1,8-pyrenodione and 9,10-anthraquinone, respectively. ${ }^{12} \mathrm{We}$ performed a PAH assay to determine the enzymatic activity of immobilized cyt $c$. Typically, $5 \mathrm{mg}$ of MPS-cyt $c$ solids were added to $5 \mathrm{~mL}$ of $20 \mu \mathrm{M}$ PAHs solution $\left(\mathrm{CH}_{3} \mathrm{CN}\right.$ : $20 \%$ and $0.05 \mathrm{M}$ of $\mathrm{KH}_{2} \mathrm{PO}_{4}-\mathrm{NaOH}$ buffer: $80 \%$ ) at $\mathrm{pH}=6.1$. After shaking the mixture for $1 \mathrm{~min}, 25 \mu \mathrm{L}$ of $200 \mathrm{mM} \mathrm{H}_{2} \mathrm{O}_{2}$ was added. The mixture was shaken again at $250 \mathrm{rpm}$ and $35^{\circ} \mathrm{C}$ for $5 \mathrm{~min}$. After the reaction was finished, the solids were separated from the reaction mixture by centrifuge. The reaction extent was determined by the intensity decrease of the absorption peaks at $335 \mathrm{~nm}$ (pyrene) and $252 \mathrm{~nm}$ (anthracene) in solution phase. Specific activity was determined by measuring the number of moles of substrate oxidized by one mole of cyt $c$ in $1 \mathrm{~min}$ and expressed as $\mathrm{min}^{-1}$. The substrate adsorption on the mesoporous support was measured in a control blank experiment: MPS-cyt $c$ solids with reaction substrate in the absence of $\mathrm{H}_{2} \mathrm{O}_{2}$. The decrease in the substrate concentration due to substrate adsorption was compensated. The percentages of physical adsorption of pyrene in substrate conversion are as follows: NaY-cyt $c$ : $11 \%$, MCM-41-S-cyt $c$ : 15\%, MCM-48cyt $c: 18 \%$, MAS-9-cyt $c: 17 \%$.

The reaction mixtures were analyzed by a Gilson 306 liquid chromatograph using an RP-18 $(4.6 \times 250 \mathrm{~mm})$ column. The mobile phase was an acetonitrile/water mixture $\left(\mathrm{CH}_{3} \mathrm{CN} / \mathrm{H}_{2} \mathrm{O}\right.$ $=70: 30$ ) with a flow rate of $1 \mathrm{~mL} / \mathrm{min}$, and a $\mathrm{UV}-$ vis detector was set at 214 or $240 \mathrm{~nm}$ wavelength. The retention times of pyrene and anthracene under these conditions were 17.58 and $12.87 \mathrm{~min}$, while the retention times of the oxidized products of pyrene and anthracene were 6.64 and $6.08 \mathrm{~min}$, respectively. The retention times and mass spectra were comparable to those of pure anthraquinone (from Fluka).

(c) Transformation of Organic Dye. Cyt $c / \mathrm{H}_{2} \mathrm{O}_{2}$ can also generate highly reactive radicals to bleach organic dyes. The reaction procedure was as follows: $5 \mathrm{mg}$ of MPS-cyt $c$ solids was added to $5 \mathrm{~mL}$ of $60 \mu \mathrm{M}$ organic dye solution at $\mathrm{pH}=6.1$ $\left(0.05 \mathrm{M} \mathrm{KH}_{2} \mathrm{PO}_{4}-\mathrm{NaOH}\right.$ buffer). After shaking the mixture for $1 \mathrm{~min}, 25 \mu \mathrm{L}$ of $200 \mathrm{mM} \mathrm{H} \mathrm{O}_{2}$ was added. The mixture was shaken again at $250 \mathrm{rpm}$ and $35{ }^{\circ} \mathrm{C}$ for $1 \mathrm{~min}$. The reaction extent is determined by the decrease of absorption peak at 601 $\mathrm{nm}$ (pinacyanol chloride) and $484 \mathrm{~nm}$ (Orange II).

(d) ESR Spin Trapping Experiments. We used tert-butyl hydroperoxide ( $t$-BuOOH, TBHP) and cumene hydroperoxide ( $\mathrm{CumOOH}, \mathrm{CHP}$ ) to study the reaction pathways of cyt $c$ in the presence of hydroperoxides. Since the decomposition of organic hydroperoxides by cyt $c$ would produce several radical species, we could gain some insight on the reaction mechanism through spin trapping experiments. All spin trapping experiments reported here were carried out at room temperature. Buffer was prepared with deionized water and treated with Chelex 100. 1 $\mathrm{mM}$ of DTPA was also added to the reaction mixture to prevent interference from free metal ions. We varied DMPO concentration to acquire different ESR spectra. The reaction mixture was vigorously shaken for $1 \mathrm{~min}$, and the liquid was withdrawn with syringe filters. The ESR spectra of the liquid were taken $5 \mathrm{~min}$ after the mixing. The reaction conditions were as follows. (i) Low DMPO concentration. The composition of a typical mixture of reagents used in the experiment was $15 \mathrm{mg}$ of MPS-cyt $c$ solids, $400 \mu \mathrm{L}$ of $0.05 \mathrm{M}$ buffer, $100 \mu \mathrm{L}$ of $10 \mathrm{mM}$ DTPA, 100 $\mu \mathrm{L}$ of $400 \mathrm{mM}$ DMPO, and $400 \mu \mathrm{L}$ of $32 \mathrm{mM}$ TBHP. (ii) High DMPO concentration. The composition of a typical mixture of reagents in this experiment was the same as above except we used $100 \mu \mathrm{L}$ of $0.05 \mathrm{M}$ buffer and $400 \mu \mathrm{L}$ of $400 \mathrm{mM}$ DMPO. Note that we kept the total volume of the mixture the same as before, therefore the concentration of DMPO was increased 4-fold here. (iii) $\mathrm{KCN}$ effect. To examine the role of heme Fe (III) center in the catalytic reaction, we added $5 \mathrm{mM} \mathrm{KCN}$ in the reaction mixture. Details: mix $15 \mathrm{mg}$ of MPS-cyt $c$ solids, $100 \mu \mathrm{L}$ of $50 \mathrm{mM} \mathrm{KCN}, 100 \mu \mathrm{L}$ of $10 \mathrm{mM}$ DTPA, $400 \mu \mathrm{L}$ of $400 \mathrm{mM}$ DMPO, and $400 \mu \mathrm{L}$ of $32 \mathrm{mM}$ TBHP.

\section{Results and Discussion}

1. Adsorption Studies. Table 1 summarizes the surface area, pore size, pore volume, and the maximum cyt $c$ loading in the aluminum-substituted MPS used in the experiments. The difference of pore size stems from the difference of organic template used. TEAOH was used as the template in the synthesis of NaY zeolite (7.4 $\AA$ ); while both TEAOH and CTAB were used in the syntheses of MCM-41-S and MCM-48-S samples. MAS-9 was synthesized by using both TPAOH and Pluronic P123 as templates. In MCM-41-S and MCM-48-S samples, TEAOH was used as template to form zeolitic nanocluster building blocks, while CTAB was used as template to form hexagonal nanochannels in the self-assembly of the aforementioned zeolitic nanoclusters. The synthetic method of MCM41-S (25 $\AA$ ) is similar to MCM-48-S (27 $\AA$ ). The only difference is that we changed the hydrothermal duration and $\mathrm{pH}$ to control the phase transition. These MPS materials have not only large surface areas (about $800-1000 \mathrm{~m}^{2} / \mathrm{g}$ ) but also proper pore size that could accommodate cyt $c$.

The amounts of adsorbed cyt $c$ were $0.68,3.18,4.35$, and $4.28 \mu \mathrm{mol} / \mathrm{g}$ for NaY, MCM-41-S, MCM-48-S, and MAS-9 in $20 \mu \mathrm{M}$ cyt $c$ aqueous solution $(\mathrm{pH}=7.5)$, respectively. As we increased the concentration of the cyt $c$ solution, the amount of adsorption increases. The maximum adsorptions were $0.97,6.35$, 4.96, and $30.52 \mu \mathrm{mol} / \mathrm{g}$ for NaY, MCM-41-S, MCM-48-S, and MAS-9, respectively. Although NaY zeolite contains more aluminum $(\mathrm{Si} / \mathrm{Al}=2.65)$, it has the smallest adsorption capacity for cyt $c$. This may be explained by the fact that its pore size is too small to accommodate the cyt $c$ molecule. On the other hand, the pore sizes of MCM-41-S and MCM-48-S ( $\mathrm{Si} / \mathrm{Al}=37)$ are just slightly larger than the molecular diameter of cyt $c$. Thus more cyt $c$ molecules can be attracted to enter their nanochannels 


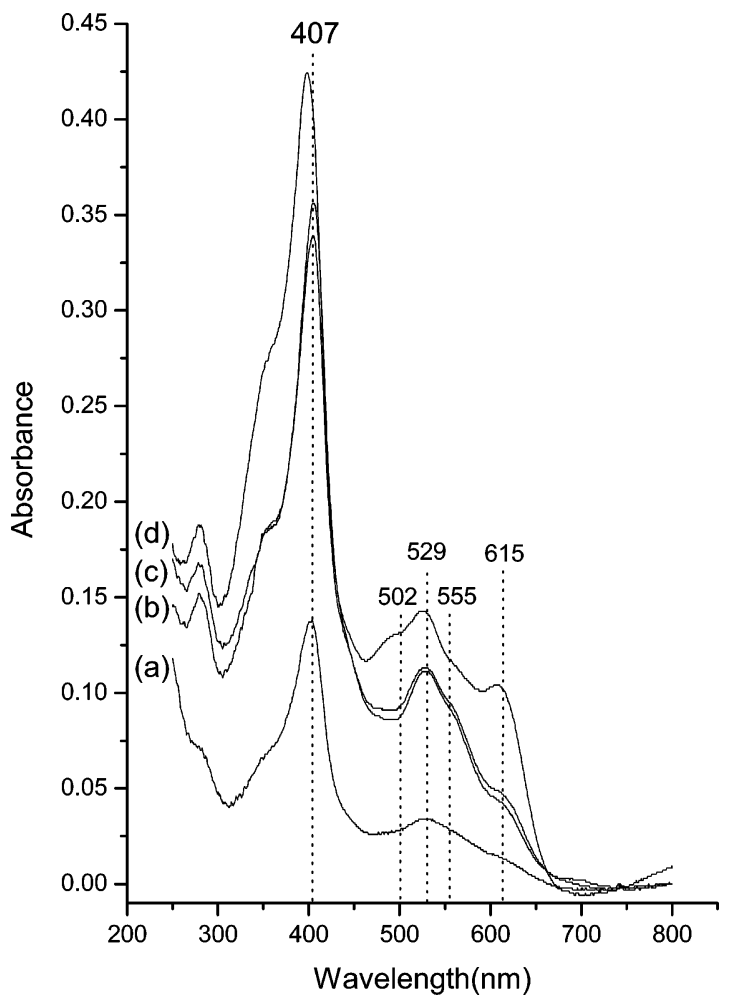

Figure 1. Diffuse reflectance UV-vis spectra of the following solid mixtures: (a) NaY-cyt $c$, (b) MCM-41-S-cyt $c$, (c) MCM-48-S-cyt $c$, and (d) MAS-9-cyt $c$.

by electrostatic force. In the low cyt $c$ concentration $(20 \mu \mathrm{M})$, MCM-48-S (2D channel) has more cyt $c$ loading capacity than MCM-41-S (1D channel). But when we increased the concentration of cyt $c$, MCM-41-S showed higher loading capacity than MCM-48-S. The high concentration of cyt $c$ seems to help it enter 1D channels. Finally, the pores of MAS-9 $(\mathrm{Si} / \mathrm{Al}=25)$ are so much larger than cyt $c$ molecules that cyt $c$ could enter in copious amount. Hence, MAS-9 has the largest cyt $c$ adsorption capacity.

Furthermore, the surface area of MPS samples is reduced by cyt $c$ adsorption, mainly because the channels are occupied by cyt $c$, which leaves less room available for nitrogen adsorption. By comparing the differences of pore volume before and after cyt $c$ adsorption, we found that the pore volume of $\mathrm{NaY}$ decreased by only $0.005 \mathrm{~cm}^{3} / \mathrm{g}$ after the adsorption; while that of others decreased by much larger amounts: MCM-41-S, 0.030; MCM-48-S, 0.288; MAS-9, $0.147 \mathrm{~cm}^{3} / \mathrm{g}$. The results indicate that cyt $c$ molecules have entered the nanochannels of MPS in large quantity. However, cyt $c$ could only be adsorbed on the external surface of microporous $\mathrm{NaY}$ zeolite, whose pore size is too small for cyt $c$ to enter, and thus the pore volume does not decrease much.

2. Spectroscopic Characterizations. (a) UV-vis Spectra. The heme group of native cyt $c$ is centered by a low-spin Fe(III) ion coordinated with six ligands, among which four ligands are nitrogen atoms of the heme group. The axial ligands are methionine 80 (Met-80) and histidine 18 (His-18). The strong field of Met ligand leads native cyt $c \mathrm{Fe}$ (III) ion in the low spin configuration. Figure 1 displays the UV-vis spectra of cyt $c$-loaded NaY zeolite, MCM-41-S, MCM-48-S, and MAS9. The Soret band absorptions at 407 and $529 \mathrm{~nm}$ are due to the absorptions of the porphyrin chromophore. Broader Q-band absorptions at 502 and $555 \mathrm{~nm}$ are from high spin and low spin heme, respectively. The band at $615 \mathrm{~nm}$ in MPS-cyt $c$ samples (absent in the native cyt $c$ ) is assigned to the in-plane charge

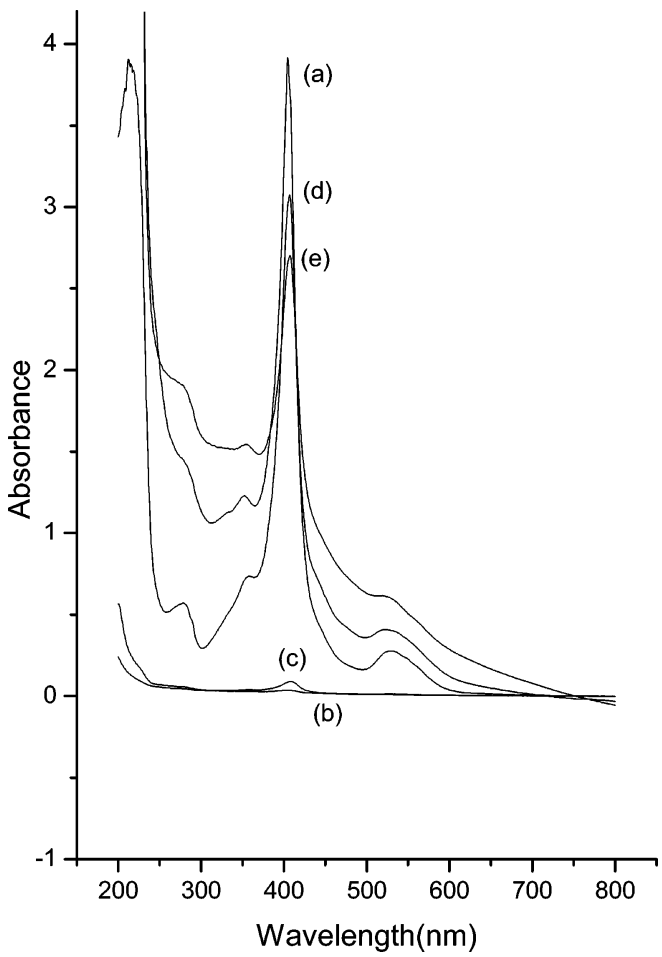

Figure 2. UV-vis spectra of the following solution mixtures: (a) solution of $40 \mu \mathrm{M}$ cyt $c$ in $\mathrm{pH}=7.5 \mathrm{KH}_{2} \mathrm{PO}_{4}-\mathrm{NaOH}$ buffer, (b) $5 \mathrm{~mL}$ of solution (a) with 0.01 g MAS-9 added, (c) solids filtered from $b$ then mixed in $20 \% \mathrm{CH}_{3} \mathrm{CN}$ and stirred for 1 day, (d) solids filtered from $\mathrm{b}$ then mixed in $\mathrm{pH}=10$ buffer and stirred for $5 \mathrm{~min}$, and (e) solids filtered from $b$ then mixed in saturated buffer $(\mathrm{pH}=7.5)$ and stirred for $3 \mathrm{~h}$.

transfer band (CT1) between the porphyrin and heme iron of the high spin heme species. The wavelength of the CT1 for cyt $c$ is mainly correlated to the axial ligand field strength. CT1 absorption with relatively low wavelength indicates the sixth ligand of heme is no longer the Met- 80 residue but is replaced by a water molecule. ${ }^{6 a}$

The MAS-9 spectrum shows a broadened and blue-shifted Soret band absorption (Figure 1d). It has been reported that the Soret band blue shift is caused by unfolding and denaturation of cyt $c .{ }^{33}$ Hence, the observed MAS-9 Soret band broadening and blue shift indicate part of cyt $c$ denature inside MAS-9 channels. This may be caused by either the conformational change due to lack of confinement inside the large pore of MAS-9 or its strong electrostatic force on cyt $c$. The latter could lead to a loss/gain of an electron and form a protein radical, which is very reactive and that could rapidly cause the enzyme to unfold and lose its activity. The presence of such a protein radical is confirmed by the ESR studies (see below in ESR section).

Figure 2 displays the UV-vis spectra of solution mixtures of cyt $c$ and MAS-9 under different conditions. Figure 2a shows the spectrum of $40 \mu \mathrm{M}$ cyt $c$ in $\mathrm{pH}=7.5$ of buffer solution. However, the strong Soret band at $407 \mathrm{~nm}$ of cyt $c$ disappeared shortly after the addition of 0.01 g MAS-9 (Figure 2b), which would indicate MAS-9 can absorb a large quantity of cyt $c$ within $10 \mathrm{~min}$. The amount of cyt $c$ leaching from MAS-9-cyt $c$ is almost undetectable in $20 \% \mathrm{CH}_{3} \mathrm{CN}$ aqueous mixture (Figure 2c), even after vigorous stirring for one full day. Note that cyt $c$ carries sufficient positive charge in $\mathrm{pH}=7.5$ buffer solution, while MAS-9 pores have negative surface charge. Hence, there is strong electrostatic attraction between cyt $c$ and MAS-9. Thus, MPS could immobilize cyt $c$ very effectively, even in the presence of water-miscible organic solvent. Fur- 
thermore, when we adjusted the $\mathrm{pH}$ to 10 , cyt $c$ surface charge became negative and cyt $c$ molecules were driven out of the channels due to strong electrostatic repulsion (Figure 2d). In another experimental condition, we added saturated buffer $\left(\mathrm{KH}_{2}-\right.$ $\left.\mathrm{PO}_{4}-\mathrm{NaOH}\right)$ at $\mathrm{pH}=7.5$ to the MAS-9-cyt $c$ solids and observed that cyt $c$ molecules were partially released due to the increase of ionic strength (Figure 2e). The released cyt $c$ solutions still have strong Soret band absorptions at $407 \mathrm{~nm}$. It indicates that most of the cyt $c$ molecules retain their original conformation during the adsorption/desorption cycle. Thus, cyt $c$ immobilized in the channels of MPS can be recycled and reused.

(b) Low-Temperature ESR Studies: Spin State of Heme Fe(III). As pointed out in the discussion of UV-vis spectra, cyt $c$ loaded in mesoporous materials exist as both low-spin and high-spin $\mathrm{Fe}(\mathrm{III})$. Low-spin $\mathrm{Fe}(\mathrm{III})$ mostly exists in native cyt $c$ and its heme axial ligands are Met-80 and His-18. High-spin $\mathrm{Fe}(\mathrm{III})$ is formed when Met-80 is replaced by $\mathrm{H}_{2} \mathrm{O}$ or a silanol group on the silica surface during the ion-exchange process of loading cyt $c$. Vazquez-Duhalt et al. chemically modified cyt $c$ with poly(ethylene glycol) and obtain the high-spin heme $\mathrm{Fe}$ (III). ${ }^{6 a, 11}$ They also reported that such high spin species could improve both the activity and stability. Hirobe et al. immobilized cyt $c$ with poly- $\gamma$-methyl-L-glutamate and found cyt $c$ with highspin Fe(III) possessing high stability in organic solvent. ${ }^{7}$ Highspin cyt $c$ has been shown to have high catalytic activity in oxidizing benzene to phenol. Its activity is improved because the heme groove is fully open and the active center is easily accessible to the substrate. Magner et al. immobilized cyt $c$ onto $\mathrm{Si}-\mathrm{MCM}-41$ and detected both low-spin and high-spin Fe(III) in Raman studies. It was also reported that high-spin Fe(III) increased the activity of peroxidase. ${ }^{24 \mathrm{~b}}$ Similarly, high-spin $\mathrm{Fe}$ (III) was observed when mesoporous carbon molecular sieves $(\mathrm{CMK}-3)^{27}$ and magnesium silicate smectite clays were used as cyt $c$ carriers. ${ }^{16}$ These reports showed that heme Fe(III) groove might change to a more stable and more active configuration with the departure of Met- 80 .

To establish the spin state of heme Fe(III), we performed ESR experiments at $10 \mathrm{~K}$. The ESR spectra are displayed in Figure 3. In NaY-cyt $c$ samples, we observed strong peak at $g$ $=4.3$, which may arise from high-spin non-heme Fe(III) (Figure $3 a)$. Here cyt $c$ attached to microporous outer surface could easily denature, break down the heme structure, and ultimately free up $\mathrm{Fe}(\mathrm{III})$ ion. In MCM-41-S- and MCM-48-S-cyt $c$ samples, we observed signals at $g=6.0$ and $g=1.99$ that is assigned to high-spin Fe(III), while signals at $g=2.93$ and $g$ $=2.30$ are assigned to low-spin Fe(III) (Figures $3 \mathrm{~b}$ and $3 \mathrm{c}$ ). ${ }^{6 \mathrm{a}}$ In the ESR spectrum of cyt $c$ embedded in MAS-9, we also observed a sharp peak at $g=2.0$ (see Figure $3 \mathrm{~d}$ ) assigned to a protein radical which may arise from strong electrostatic force on cyt $c$, lead to electron transfer, and cause parts of the enzyme to unfold and lose its activity. This is consistent with the broadened and blue-shifted Soret band absorption observed in MAS-9-cyt $c$ samples and is an indication that cyt $c$ is partially denatured.

We further studied the spin state of heme Fe(III) of MCM48-S-cyt $c$ sample treated with a solution of $1 \mathrm{mM} \mathrm{H}_{2} \mathrm{O}_{2}$ (Figure $3 e)$. In comparison with the spectrum obtained before the $\mathrm{H}_{2} \mathrm{O}_{2}$ treatment (Figure 3c), we found that the ESR signal intensity at $g=6.0$ of high-spin Fe(III) decreased, which is probably due to the oxidation of heme Fe(III) to heme Fe(IV) during the reaction. The appearance of strong signal at $g=4.3$ due to free $\mathrm{Fe}(\mathrm{III})$ ions may result from the damage by reactive hydroxyl radicals. The sharp signal at $g=2.0$ is ascribed to

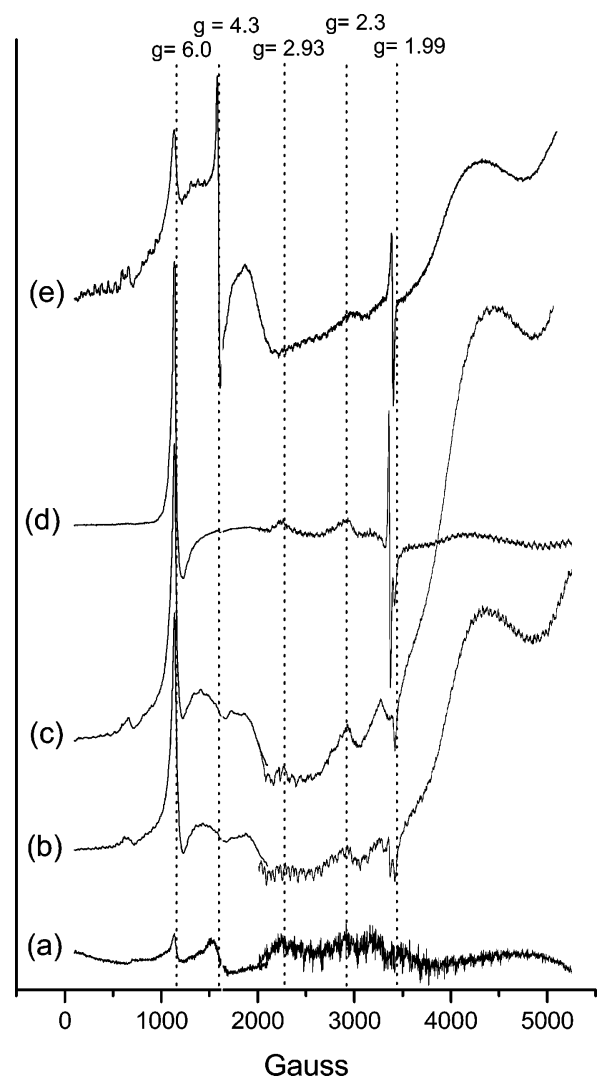

Figure 3. ESR spectra at $10 \mathrm{~K}$ of cyt $c$ immobilized on (a) NaY, (b) MCM-41-S, (c) MCM-48-S, (d) MAS-9, and (e) MCM-48-S-cyt $c$ treated with $\mathrm{H}_{2} \mathrm{O}_{2}$.

\section{SCHEME 1. Proposed Mechanism of $\mathrm{PAH}-\mathrm{H}_{2} \mathrm{O}_{2}$ Oxidation Catalyzed by Cytochrome $c$ Immobilized in the Nanochannels of MPS}
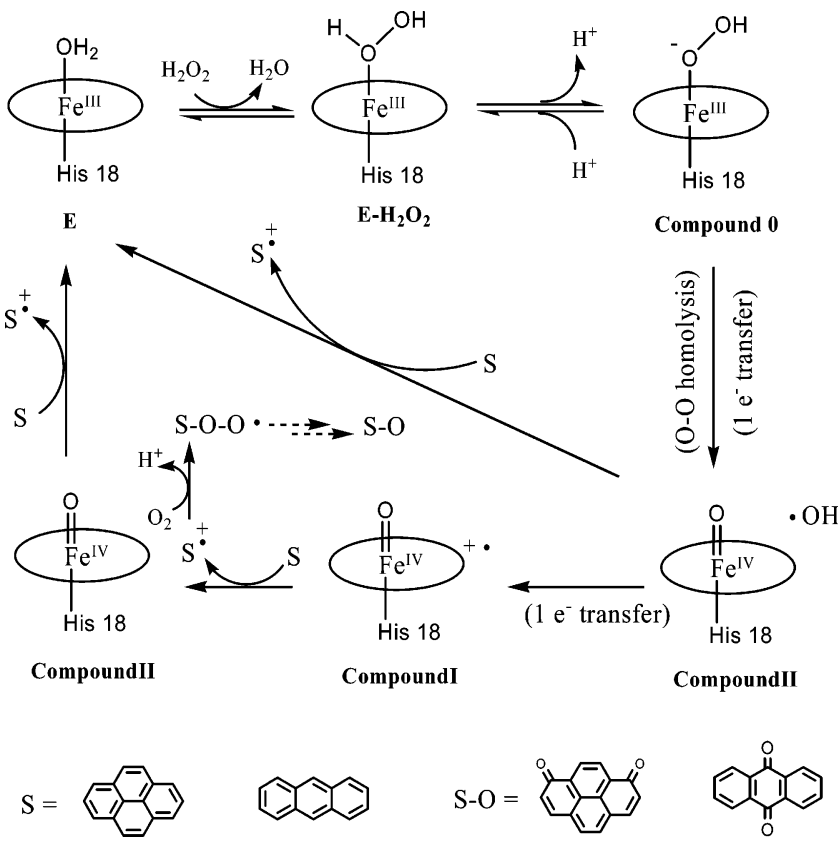

protein radical compound I, which is formed from compound II by transferring one electron to hydroxyl radical. ${ }^{34}$ The details of these pathways are given in Scheme 1.

3. Cleavage of Organic Hydroperoxides. We performed two sets of experiments to examine the stability and reaction pathways in the cleavage of organic hydroperoxides by MPScyt $c$ samples. 


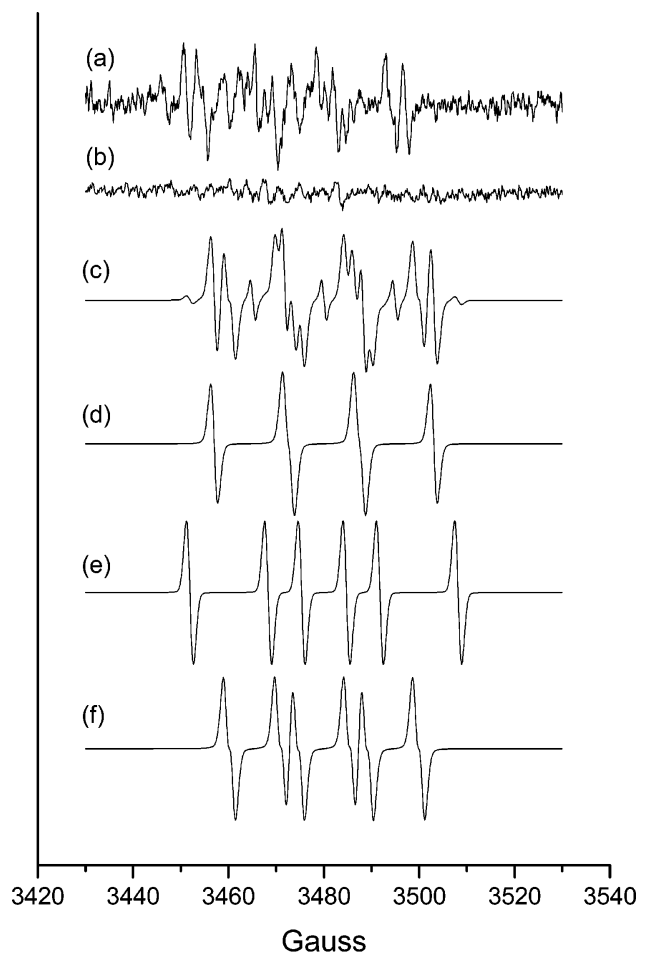

Figure 4. ESR spectra of DMPO radical adducts from (a) incubations of $15 \mathrm{mg}$ of MCM-48-S-cyt $c, 12.8 \mathrm{mM} \mathrm{t}-\mathrm{BuOOH}$ and $40 \mathrm{mM}$ DMPO, (b) control - no cyt $c$ solid added, and (c) computer simulated spectrum consists of $38 \% \mathrm{DMPO} / \cdot \mathrm{OC}\left(\mathrm{CH}_{3}\right)_{3}, 2 \% \mathrm{DMPO} / \cdot \mathrm{CH}_{3}, 56 \% \mathrm{DMPO} / \cdot$ OOR, and $4 \%$ DMPO oxide. $(\mathrm{d}-\mathrm{f})$ Simulated spectra of the individual spin adducts: (d) DMPO/ $\cdot \mathrm{OC}\left(\mathrm{CH}_{3}\right)_{3}$, (e) DMPO/ $\cdot \mathrm{CH}_{3}$, and (f) DMPO/ -OOR.

(a) ESR Spin Trapping Experiments. The ESR spin trapping spectrum recorded for the reaction of $15 \mathrm{mg}$ of MCM-48-S-cyt $c$ and $12.8 \mathrm{mM} t$-BuOOH in $40 \mathrm{mM}$ DMPO is shown in Figure 4a. The spectrum could arise from a mixture of four DMPO adducts, and a simulated spectrum ${ }^{35}$ with the following contribution is displayed in Figure 4c: (a) $38 \%$ of tert-butyloxyl, $a^{\mathrm{N}}$ $=14.9 \mathrm{G}, a^{\mathrm{H} \beta}=16.2 \mathrm{G}$ (Figure $4 \mathrm{~d}$ ), (b) $2 \%$ of methyl, $a^{\mathrm{N}}=$ $16.4 \mathrm{G}, a^{\mathrm{H} \beta}=23.4 \mathrm{G}$ (Figure $4 \mathrm{e}$ ), (c) $56 \%$ of peroxyl (methyl peroxyl), $a^{\mathrm{N}}=14.45 \mathrm{G}, a^{\mathrm{H} \beta}=10.75 \mathrm{G}, a^{\mathrm{Hr}}=1.35 \mathrm{G}$ (Figure $4 \mathrm{f}$ ), and (d) $4 \%$ of a DMPO oxidized product, $a^{\mathrm{N}}=14.9 \mathrm{G}$. These hyperfine values are the same as previously reported. ${ }^{36}$

We further observed similar results with cumene hydroperoxide (data not shown). When MPS-cyt $c$ is absent in the reaction mixture (control), we observed only very weak signal as shown in Figure 4b (also in Figure 5f). The ESR experiments indicate that the generation of radical adducts takes place only in the presence of cyt $c$ and hydroperoxides. Thus, cyt $c$ plays an important role in the decomposition of hydroperoxides.

Because we could trap the initial radical intermediate and form stable DMPO adducts by using high concentrations of DMPO, we could then determine which radical is the primary initial radical among multiple species. ${ }^{36,37}$ We therefore increased DMPO concentration four-fold to $160 \mathrm{mM}$ in the subsequent ESR spin trapping experiments. Figure 5 shows the ESR spectra of DMPO radical adducts generated by different MPS carriers that adsorbed the same amount of cyt $c(2 \mu \mathrm{mol}$ cyt $c$ per gram of MPS except $0.7 \mu \mathrm{mol}$ cyt $c$ per gram of $\mathrm{NaY}$ ) in the presence of $12.8 \mathrm{mM} t-\mathrm{BuOOH}$ and $160 \mathrm{mM}$ DMPO.

The signal strength follows the order NaY (Figure 5a) < MCM-41-S (Figure 5b) < MCM-48-S (Figure 5c) < MAS-9 (Figure 5d). We note that NaY-cyt $c$ has the least signal strength, which indicates cyt $c$ has low loading of cyt $c$. On the other hand, MCM-41-S and MCM-48-S have similar pore size to

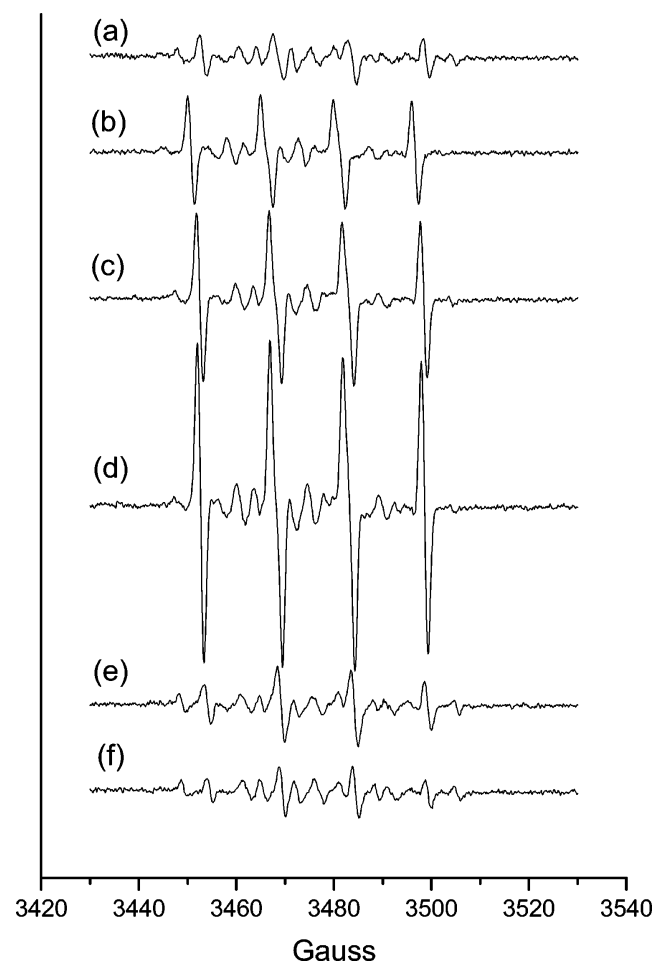

Figure 5. ESR spectra of DMPO radical adducts from incubations of $12.8 \mathrm{mM} t$-BuOOH, $160 \mathrm{mM}$ DMPO and $15 \mathrm{mg}$ of the following solids: (a) NaY-cyt $c$, (b) MCM-41-S-cyt $c$, (c) MCM-48-S-cyt $c$, (d) MAS-9-cyt $c$ and (e) same as d except $5 \mathrm{mM}$ of KCN was added before reaction, and (f) control - no cyt $c$ solid added.

accommodate cyt $c$. Furthermore, they provide proper confined spaces and adequate surface charge to stabilize the immobilized cyt $c$ molecules. However, MCM-48-S has 3D channel structure, which provides better diffusion and mobility than MCM-41-S 1D channel structure. Thus, alkoxyl radicals formed inside MCM-48-S pores can diffuse into solution rapidly and give rise to a stronger signal. ${ }^{38}$ Finally, MAS-9 has extra large pores that would allow alkoxyl radicals to exit freely and give the strongest signal.

To study the function of the heme Fe(III) center in the catalytic reaction, we added $5 \mathrm{mM} \mathrm{KCN}$ to the substrate. We observed that the intensity of the alkoxyl radical signal reduced drastically (Figure 5e). Cyanide coordinates with the heme Fe(III) of cyt $c$ at the sixth axial position and thereby inhibits hydroperoxide to approach heme Fe(III). Thus, we may conclude that peroxide needs to coordinate with heme $\mathrm{Fe}(\mathrm{III})$ for the catalytic reaction to take place.

(b) Cleavage Mechanism. Several mechanisms for the cleavage of hydroperoxide catalyzed by heme protein have been proposed. ${ }^{36,37}$ The most commonly contended mechanisms are given below which critically depend on the formation pathway of the primary initial radical. ${ }^{36,37}$ Based on the ESR spectra measured with high DMPO concentration (Figure 5), we could therefore establish the cleavage mechanism as follows.

(i) Heterolytic Mechanism. The reaction is taking place in the following steps: (1) $t$ - $\mathrm{BuOOH}$ undergoes 2-electron reduction to t-BuOH while cyt $c$ is oxidized to a compound I type species (see equations given below). (2) Compound I abstracts hydrogen atom from $t$ - $\mathrm{BuOOH}$, which subsequently becomes peroxyl radical (the initial radical). (3) Tertiary peroxyl radicals react with each other and form two alkoxyl radicals and $\mathrm{O}_{2}$. (4) Alkoxyl radicals form methyl radicals through $\beta$-scission. The first radical formed through the heterolytic mechanism is a tertiary peroxyl radical. Hence, if heterolytic mechanism is 
correct we should be able to capture tertiary peroxyl radicals and inhibit the formation of alkoxyl and methyl radicals by increasing DMPO concentration. The reaction steps are summarized in the following equations:

$\mathrm{Cyt} . \mathrm{c}-\mathrm{Fe}(\mathrm{III})+\mathrm{t}-\mathrm{BuOOH} \longrightarrow \mathrm{Cyt} \cdot \mathrm{c} \cdot \stackrel{-}{\stackrel{\mathrm{O}}{\mathrm{Fe}}(\mathrm{IV})}+\mathrm{t}-\mathrm{BuOH}$

Cyt.c $\stackrel{+}{\stackrel{\text { II }}{\mathrm{Fe}}(\mathrm{IV})}+\mathrm{t}-\mathrm{BuOOH} \longrightarrow$ Cyt.c- $\stackrel{\text { Fe}}{\longrightarrow}(\mathrm{III})+\mathrm{t}-\mathrm{BuOO}$.

$\mathrm{t}-\mathrm{BuOO} \cdot+\mathrm{t}-\mathrm{BuOO} \cdot \longrightarrow 2 \mathrm{t}-\mathrm{BuO} \cdot+\mathrm{O}_{2}$

$\mathrm{t}-\mathrm{BuO} \cdot \longrightarrow \cdot \mathrm{CH}_{3}+$ Acetone

(ii) Homolytic Mechanism. Here the $\mathrm{O}-\mathrm{O}$ bond of $t$ - $\mathrm{BuOOH}$ could go through homolytic scission and form tertiary alkoxyl radicals, which go through $\beta$-scission and form methyl radicals and acetone. Methyl radicals could react with oxygen and become methyl peroxyl radicals. Thus, the tertiary alkoxyl radical is the first radical formed in the homolytic mechanism. Experimentally, the tertiary alkoxyl radical signal should increase when we increase the concentration of DMPO. The reaction steps are summarized in the following equations:

$$
\begin{gathered}
\text { Cyt.c-Fe(III) }+ \text { t-BuOOH } \longrightarrow \text { Cyt.c- } \stackrel{\text { Fe}(I V)+t-B u O}{\longrightarrow} \\
\mathrm{t}-\mathrm{BuO} \cdot \longrightarrow \cdot \mathrm{CH}_{3}+\text { Acetone } \\
\cdot \mathrm{CH}_{3}+\mathrm{O}_{2} \longrightarrow \cdot \mathrm{OOCH}_{3}
\end{gathered}
$$

(iii) Haber-Weiss-type Mechanism. Here $t$-BuOOH is first oxidized by one electron to peroxyl radical, with the concomitant reduction of cyt $c \mathrm{Fe}$ (III) to $\mathrm{Fe}(\mathrm{II})$, which could further reduce another $t$-BuOOH molecule to alkoxyl radical (Fenton-type reaction). Then, peroxyl radical is the radical formed initially, followed by alkoxyl radical. Thus, when we increase DMPO concentration we should see both peroxyl radical and alkoxyl radical signals increase if this mechanism is correct. The reaction steps are summarized in the following equations:

$$
\begin{aligned}
& \text { Cyt.c-Fe(III) }+ \text { t-BuOOH } \longrightarrow \text { Cyt.c-Fe(II) }+ \text { t-BuOO } \cdot \\
& \text { Cyt.c-Fe(II) }+ \text { t-BuOOH } \longrightarrow \text { Cyt.c-Fe(III) }+ \text { t-BuO } .
\end{aligned}
$$

As careful examination of Figures 4 and 5 shows, we note that several species of radical adducts (peroxyl, alkoxyl, methyl radicals) are detected at low DMPO concentration, while alkoxyl radical adduct is the primary product observed at high DMPO concentration. We therefore conclude that the cleavage of hydroperoxides follows the homolytic cleavage mechanism where cyt $c$ immobilized in MPS first breaks down $\mathrm{O}-\mathrm{O}$ bond to form alkoxyl radicals and cyt $c$ - $\mathrm{Fe}(\mathrm{IV})=\mathrm{O}$ (often referred to as compound II). Both methyl and methyl peroxide radicals are the subsequent secondary radicals formed by alkoxyl radicals. The same reaction pathways were also reported in the decomposition of hydroperoxides by native cyt $c$ (low spin state). ${ }^{36} \mathrm{~A}$ detailed catalytic mechanism including the oxidation of PAH is proposed in Scheme 1.

(c) Hydrothermal Stability. (i) Changes in Soret Band Intensity. It has been hypothesized that the heme Fe(III) center

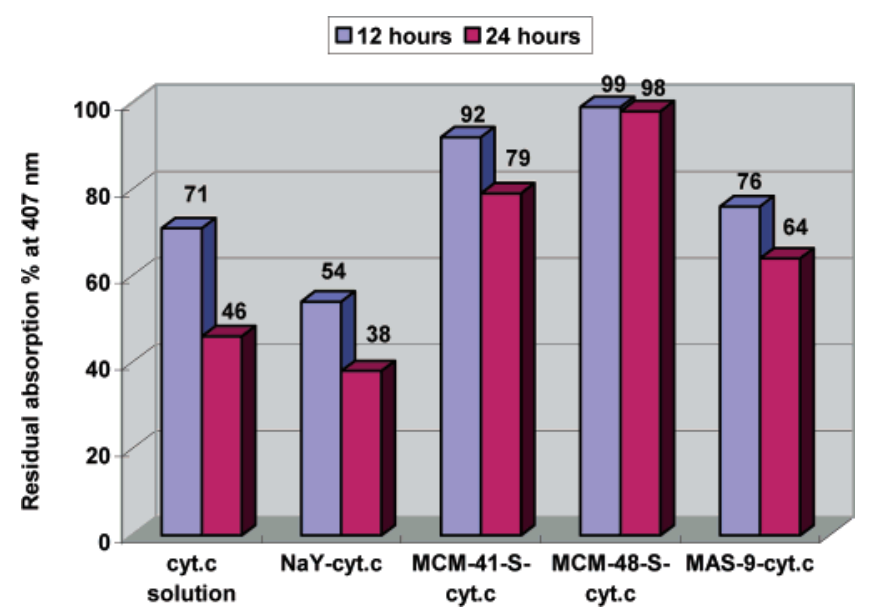

Figure 6. Percentile residual absorption intensity at $407 \mathrm{~nm}$ (Soret band) after 12-h and 24-h hydrothermal treatment at $100{ }^{\circ} \mathrm{C}$. Residual absorption \% at $407 \mathrm{~nm}=\{(\mathrm{AH}) /(\mathrm{BH})\} \times 100 ;(\mathrm{BH})=\mathrm{UV}-$ vis absorption at $407 \mathrm{~nm}$ before hydrothermal; $(\mathrm{AH})=$ absorption after hydrothermal.

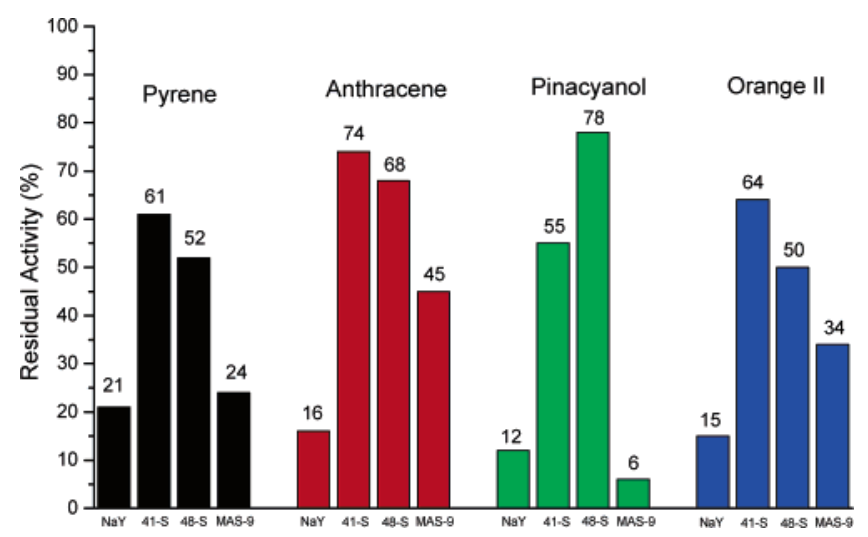

Figure 7. Residual catalytic activity of MPS-cyt $c$ samples with PAHs and organic dyes by $\mathrm{H}_{2} \mathrm{O}_{2}$ after 24-h hydrothermal treatment at 100 ${ }^{\circ} \mathrm{C}$. The results for $12-\mathrm{h}$ treatment are given in the Supporting Information S2.

breaks down irreversibly during hydrothermal heating at 100 ${ }^{\circ} \mathrm{C}$ and frees up $\mathrm{Fe}$ (III) ions, which is evidenced by the irreversible decrease of Soret band absorption. ${ }^{11}$ Figure 6 shows the percentile residual Soret band absorption intensity of various MPS-cyt $c$ samples after $12 \mathrm{~h}$ and $24 \mathrm{~h}$ of hydrothermal treatments at $100{ }^{\circ} \mathrm{C}$. We observed that MCM-41-S-cyt $c$ and MCM-48-S-cyt $c$ maintained strong Soret band absorption after heating: $79 \%$ and $98 \%$ retained, respectively, after 24-h hydrothermal treatment. On the other hand, NaY-cyt $c$ and MAS-9-cyt $c$ showed substantial losses of Soret band absorption that are even more than the native cyt $c$ solution. We attribute the extraordinary stability of cyt $c$ in MCM-41-S and MCM$48-\mathrm{S}$ to the protection provided by proper confinement space.

(ii) Residue in Catalytic Activity. Figure 7 shows the residual percentile catalytic activity of various MPS-cyt $c$ samples after 24-h hydrothermal treatment at $100{ }^{\circ} \mathrm{C}$. The results for the $12-\mathrm{h}$ treatment are given in the Supporting Information S2. The heattreated MCM-41-S and MCM-48-S samples retain $61 \%$ and $52 \%$, respectively, of the initial activity in the oxidation of pyrene, while MAS-9 and NaY only have $24 \%$ and $21 \%$, respectively, of the initial activity. The same order of residual activity holds for the oxidation of other substrates: anthracene, pinacyanol and orange II.

Previously, Takahashi et al. reported horseradish peroxidase immobilized in $\mathrm{Si}-\mathrm{MCM}-41$ of different pore size $(27-92 \AA)$ 


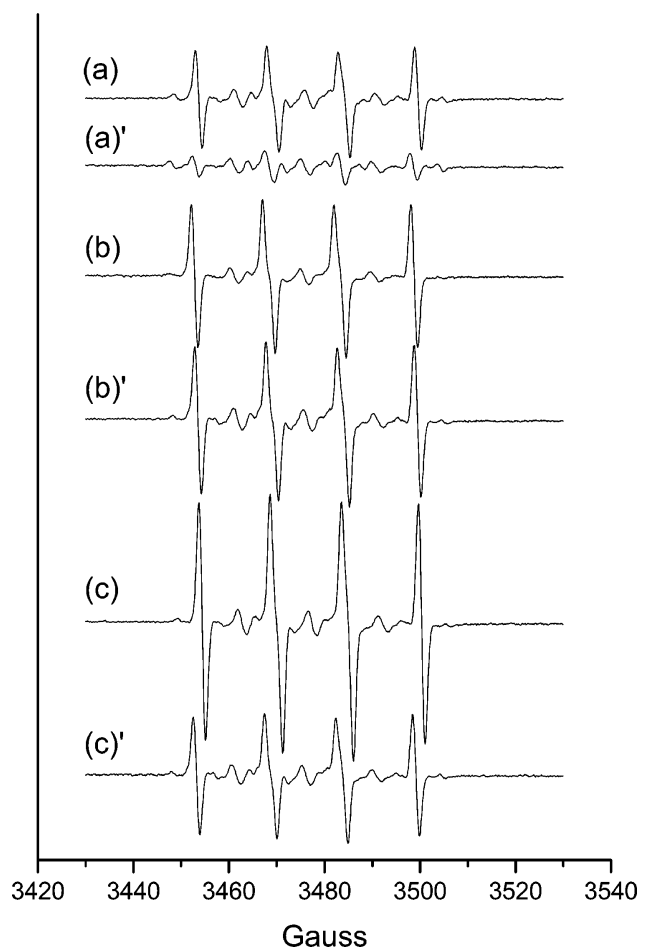

Figure 8. ESR spectra of DMPO/ $\cdot \mathrm{OC}\left(\mathrm{CH}_{3}\right)_{3}$ radical observed in the cleavage of hydroperoxides, before $(a, b, c)$ and after $\left(a^{\prime}, b^{\prime}, c^{\prime}\right)$ hydrothermal treatment at $100{ }^{\circ} \mathrm{C}$ for $24 \mathrm{~h}$, with (a) NaY-cyt $c$, (b) MCM-48-S-cyt $c$, and (c) MAS-9-cyt $c$ samples.

and measured catalytic activity in the oxidation of 1,2diaminobenzene. ${ }^{25 a, b}$ They inferred that enzymes embedded in a material, whose pore size just matches enzyme molecular size, would have the highest activity and stability, while enzymes embedded in large-pore materials would have lower activity and stability. The least stability and activity were ascribed to enzymes in materials with relatively small pores. The results of our work are consistent with Takahash's conclusions. MCM41-S and MCM-48-S have pore sizes in the range of $25-27 \AA$, which are the best match to the cyt $c$ molecule $(25 \times 25 \times 37$ $\AA),{ }^{39}$ and they showed undoubtedly the best hydrothermal stability. Their matching size further provides confined spaces that prevent cyt $c$ from unfolding and heme from decomposing during the heating process.

(iii) Activity toward the Decomposition of t-BuOOH. Figure 8 displays the ESR spectra obtained in spin trapping experiments. It shows the effect of hydrothermal treatment on MPScyt $c$ catalytic activity on the cleavage of the $\mathrm{O}-\mathrm{O}$ bond of peroxides. The MPS-cyt $c$ samples were heated in buffer solution at $100{ }^{\circ} \mathrm{C}$ for $24 \mathrm{~h}$ prior to spin trapping measurements. The heat-treated MPS-cyt $c$ samples were added into the $t$-BuOOH-DMPO mixture to react for one min before the ESR spectra were taken (Figure 8 $8 a^{\prime}, 8 b^{\prime}$ and $8 c^{\prime}$ ). We also performed the same ESR measurements with unheated cyt $c$-MPS samples for comparison (Figure 8a, 8b and 8c). MCM-48-S-cyt $c$ retained its catalytic activity as evidenced by the fact that intensity of alkoxyl radical remained almost the same after 24-h of hydrothermal treatment (Figure $8 b$ and $8 b^{\prime}$ ). However, both NaY-cyt

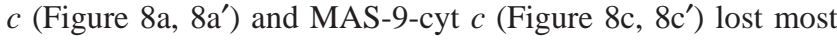
of their catalytic activity after hydrothermal treatment. We believe that MCM-48-S offers adequate surface charge and properly confined spaces so that embedded cyt $c$ can maintain its folding conformation at high temperature and retain its enzymatic activity. On the other hand, cyt $c$ can only attach to zeolite pore outer surface of $\mathrm{NaY}$ zeolite; therefore cyt $c$ loses
TABLE 2: Specific Catalytic Activity of MPS-cyt $c$ Samples to Different Substrate with $\mathrm{H}_{2} \mathrm{O}_{2}$

\begin{tabular}{lcccc}
\hline \multirow{2}{*}{ sample } & \multicolumn{3}{c}{ specific activity $\left(\mathrm{min}^{-1}\right)$ of biocatalytic oxidation } \\
\cline { 2 - 5 } & pyrene & anthracene & pinacyanol & orange II \\
\hline NaY-cyt $c$ & 0.16 & 0.49 & 3.93 & 0.87 \\
MCM-41-S-cyt $c$ & 0.18 & 0.56 & 12.30 & 0.60 \\
MCM-48-S-cyt $c$ & 0.17 & 0.64 & 10.93 & 0.56 \\
MAS-9-cyt $c$ & 0.19 & 1.08 & 2.61 & 0.99
\end{tabular}

its activity rapidly. MAS-9 pore size is so large that, when heated, cyt $c$ can easily change conformation and lose enzymatic activity.

Consequently, the Soret band absorption intensity of cyt $c$ decreases irreversibly, which leads to partial loss of cyt $c$ activity in the oxidation of substrate and decrease the decomposition of $t$-BuOOH that forms alkoxyl radicals. Thus, the measured Soret band intensity is positively correlated to the remaining catalytic activity.

4. Oxidation of Polycyclic Aromatic Hydrocarbons. (a) Activity Measurements. We study the oxidation activity of MPScyt $c$ samples in the presence of $\mathrm{H}_{2} \mathrm{O}_{2}$ toward two types of PAHs (pyrene and anthracene) and two types of organic dyes (pinacyanol and orange II). MPS surface is highly hydrophilic because of the presence of many silanol groups. Hydrophilic pores attract a large quantity of cyt $c$ to enter. Pyrene and anthracene are both hydrophobic molecules, thus, they enter MPS pores slowly by diffusion process. Hence, the reaction rate is limited by their transfer rate. On the other hand, pinacyanol, a hydrophilic organic dye, can enter and exit MPS pores freely and rapidly. Therefore, its reaction rate is not limited by the mass transfer rate. The results are summarized in Table 2. The specific activity is defined as moles of substrate oxidized per mole of cyt $c$ in $1 \mathrm{~min}$ and expressed as $\min ^{-1}$.

We note that MAS-9-cyt $c$ shows the largest specific activity toward pyrene and anthracene oxidation (pyrene $=0.19$, anthracene $=1.08 \mathrm{~min}^{-1}$ ). Such a high activity is due to the fact that MAS-9 pores are the largest. Pyrene and anthracene molecules can rapidly diffuse into MAS-9 pores. Hence, the oxidation takes place easily. NaY-cyt $c$ shows the least activity for both pyrene and anthracene oxidation (pyrene $=0.16$, anthracene $=0.49 \mathrm{~min}^{-1}$ ), because cyt $c$ could only attach to $\mathrm{NaY}$ microporous outer surface and loses activity easily in $20 \%$ of $\mathrm{CH}_{3} \mathrm{CN}$ solution.

MCM-41-S-cyt $c$ and MCM-48-S-cyt $c$ show the highest activity (12.30 $\mathrm{min}^{-1}$ and $10.93 \mathrm{~min}^{-1}$, respectively) for pinacyanol oxidation. As we pointed out earlier, pinacyanol is hydrophilic and its reaction rate is not affected by transfer rate. Moreover, MCM-41-S and MCM-48-S provide confined spaces to protect the embedded cyt $c$ molecules from conformation change. On the other hand, cyt $c$ does not have confinement and very strong interaction between cyt $c$ and MAS-9. The Soret band broadening and blue shift in UV-vis spectra have shown the unfolding and denaturation of cyt $c$ in MAS-9. It was further evidenced by the presence of a protein radical observed in the ESR studies. These findings indicate that some cyt $c$ molecules lost enzymatic activity inside MAS-9 channels. This explains why MAS-9-cyt $c$ activity $\left(2.61 \mathrm{~min}^{-1}\right)$ is smaller than MCM41-S and MCM-48-S.

To further examine the effect of substrate diffusion rate on catalytic activity, we studied various MPS-cyt $c$ as catalysts in the oxidation of negatively charged organic dye (orange II) by $\mathrm{H}_{2} \mathrm{O}_{2}$. Since negatively charged pores exert strong electrostatic repulsion to orange II molecules, the mass transfer is governed by slow diffusion process. Not surprisingly, the results are similar to the cases for pyrene and anthracene. MAS-9 has the 
highest activity $\left(0.99 \mathrm{~min}^{-1}\right)$ for its highest diffusion rate due to its large pores. Microporous NaY-cyt $c$ also has relatively high activity $\left(0.87 \mathrm{~min}^{-1}\right)$ because cyt $c$ molecules are attached to the outer surface and easily accessible. In another experiment, the reaction in a buffer solution $\left(\mathrm{KH}_{2} \mathrm{PO}_{4}-\mathrm{NaOH}\right)$ only did not cause the NaY-cyt $c$ sample to unfold and denature. However, MCM-41-S-cyt $c$ and MCM-48-S-cyt $c$ activities are relatively small, 0.60 and $0.56 \mathrm{~min}^{-1}$, respectively.

(b) Catalytic Mechanism. Based on our spectroscopic studies, we propose a catalytic oxidation mechanism of PAHs, as illustrated in Scheme 1. From UV-vis and low-temperature ESR studies of cyt $c$ embedded in MPS, we assigned the heme $\mathrm{Fe}(\mathrm{III})$ center to high spin state, where Met- 80 is replaced by $\mathrm{H}_{2} \mathrm{O}$ or silanol group on silica surface (E state in Scheme 1). From ESR spin trapping experiments, we learned that $5 \mathrm{mM}$ $\mathrm{KCN}$ could deactivate cyt $c$ almost completely, and we concluded that hydroperoxide must coordinate with heme $\mathrm{Fe}$ (III) to form the $\mathrm{E}-\mathrm{H}_{2} \mathrm{O}_{2}$ intermediate. The $\mathrm{E}-\mathrm{H}_{2} \mathrm{O}_{2}$ state subsequently loses a proton and becomes compound 0 . From the ESR experiments with high DMPO concentration, we found that alkoxyl radical is the first radical generated in the reaction and it comes from the homolytic cleavage of $\mathrm{O}-\mathrm{O}$ bond. Hence, through homolytic scission of $\mathrm{O}-\mathrm{O}$ bond, compound 0 forms compound II by releasing a hydroxyl radical, and produces a protein radical cation $\left(\mathrm{P}^{\bullet+}\right)$ intermediate, compound I, by one electron transfer. The oxidized enzyme $\left(\mathrm{P}^{\bullet+}\right)$ is the origin of the low-temperature ESR signal at $g \approx 2.0$. The radicals generated in a protein may migrate in an intramolecular pathway through the protein backbone following a redox gradient. We have yet been able to determine which amino acid residue carries the unpaired electron. Thus, we just show compound I as a simple radical cation intermediate in Scheme 1. However, it has been reported that four radical sites are formed in the reaction of cyt $c$ with $\mathrm{H}_{2} \mathrm{O}_{2}$, and at least one of them is a tyrosyl radical at the $\mathrm{C}-1$ position. ${ }^{40}$ Compound $\mathrm{I}$ is further reduced back to compound II by an electron donor substrate (S). A second substrate can reduce Fe(IV) of compound II back to Fe(III) (E state). Substrate (S) becomes cation radical $\left(\mathrm{S}^{\bullet+}\right)$ by losing one electron to the enzyme. $S^{\bullet+}$ is further oxidized to the final product $\mathrm{S}-\mathrm{O}$. The mechanism for this second oxidation is not clear, but one may envision that $S^{\bullet+}$ reacts with molecular dioxygen accompanying the release of a proton to form $\mathrm{S}-\mathrm{O}-$ $\mathrm{O}^{\bullet}$ radical intermediate, which becomes $\mathrm{S}-\mathrm{O}$ by cleaving the $\mathrm{O}-\mathrm{O}$ bond of the adduct as shown in Scheme 1 .

\section{Conclusions}

Our study shows that the enzyme immobilization can improve not only the enzymatic activities but also the enzyme stability by protecting it against high temperature and organic solvent. We found that a good MPS carrier for cyt $c$, and enzyme in general, should meet the following two stabilization factors: (a) proper pore size (it must match the size between the MPS pores and enzyme molecules where proper confined spaces could stabilize and prevent enzyme from losing its folding conformation), and (b) adequate interaction (it must provide a negatively charged pore surface, e.g., by Al substitution, to electrostatically interact with the positively charged enzyme which could improve the adsorption of enzyme in nanochannels and prevent the enzyme from leaching).

In our study, a large quantity of cyt $c$ has been immobilized in the nanochannels of MPS by electrostatic attraction under biocompatible $\mathrm{pH}$ conditions. Immobilized cyt $c$ has high hydrothermal stability and improved catalytic activities. MAS-9 has the highest loading capacity because of its extra-large pore size and pore volume. However, MAS-9-cyt $c$ loses its catalytic activities due to protein unfolding after prolonged heating. MCM-41-S-cyt $c$ and MCM-48-S-cyt $c$ retain the highest catalytic activity after extended hydrothermal heating, because they offer a cyt $c$ constricting environment that inhibits cyt $c$ from unfolding and from irreversible decomposition. Since the pore size of Y zeolite is relatively small that cyt $c$ molecules can only attach to its external surface, cyt $c$ molecules supported on $\mathrm{Y}$ zeolite are the least stable.

UV-vis and ESR studies showed that cyt $c$ immobilized in MPS adopts a high-spin Fe(III) state and yields new catalytic activities. Furthermore, ESR spin trapping experiments showed that hydroperoxides have to coordinate with heme Fe(III) for the catalytic reaction to proceed. By increasing the concentration of DMPO in ESR experiments, we also determined the key step of the catalytic decomposition of hydroperoxides in MPS-cyt $c$ to be the homolytic cleavage of the $\mathrm{O}-\mathrm{O}$ bond, whose products are compound II and hydroxyl radical. Compound II further loses one electron and becomes compound I, a protein radical intermediate. Meanwhile electron donor substrate S transfers one electron to compound II or I and becomes a cation radical $\mathrm{S}^{\bullet+}$, which is further oxidized to the corresponding oxide, $\mathrm{SO}$, although the mechanism for $\mathrm{S}^{\bullet+}$ oxidation is still not clear.

The immobilization of enzyme in mesoporous aluminosilicate offers one great opportunity in further controlling the microenvironment of enzyme, which enables us to explore catalytic actions in "unnatural conditions", such as extreme temperature or solvent conditions. Further complex organization of the enzyme-coenzymes inside the nanopore could be explored to design very interesting catalytic assembly. An exciting recent example is a reported nanoscale organization of chlorophyll a in mesoporous silica for solar energy conversion. ${ }^{41}$ This work shows through confinement of enzymes that one can control the electronic state of metal center in addition to the stabilization of protein folding. With further incorporation of other molecules and complex organizations of enzyme and co-enzymes, one can develop more interesting nanoscale organization of proteins in mesoporous environments.

Acknowledgment. This work was supported by a grant from the Ministry of Education of Taiwan through Academy Excellent program. T.-S.L. acknowledges partial support by a grant from NSF (INT0115082) and a PRF grant administered by the American Chemical Society (36970). We wish to thank Prof. S.-C. Ke of NDHU for assisting us to acquire the liquid helium ESR spectra.

Supporting Information Available: Powder X-ray diffraction spectra and catalytic activity of MPS-cyt c samples. This material is available free of charge via the Internet at http:// pubs.acs.org.

\section{References and Notes}

(1) Stryer, L. Biochemistry, 4th ed.; W. H. Freeman: New York, 1995.

(2) (a) Akasaka, R.; Mushino, T.; Hirobe, M. Arch. Biochem. Biophys. 1993, 301, 355. (b) Vazquez-Duhalt, R.; Westlake, D. W. S.; Fedorak, P. M. Enzyme Microb. Technol. 1993, 15, 494. (c) Ryu, K.; Kim, J.; Heo, J.; Chae, Y. Biotechnol. Lett. 2002, 24, 1535. (d) Ryu, K.; Heo, J. C.; Yoo, I. K. Biotechnol. Lett. 2002, 24, 143. (e) Vazquez-Duhalt, R.; Westlake, D. W. S.; Fedorak, P. M. Enzyme Microb. Technol. 1993, 15, 494.

(3) Radi, R.; Thomson, L.; Rubbo, H.; Prodanov, E. Arch. Biochem. Biophys. 1991, 288, 112. 1219 .

(4) Fujita, A.; Senzu, H.; Kunitake, T.; Hamachi, I. Chem. Lett. 1994,

(5) Deere, J.; Magner, E.; Wall, J. G.; Hodnett, B. K. Biotechnol. Prog. 2003, 19, 1238. 
(6) (a) Busi, E.; Howes, B. D.; Pogni, R.; Basosi, R.; Tinoco, R.; Vazquez-Duhalt, R. J. Mol. Catal. B: Enzymol. 2000, 9, 39. (b) Torres, E.; Tinoco, R.; Vazquez-Duhalt, R. Wat. Sci. Technol. 1997, 36, 37.

(7) Akasaka, R.; Mashino, T.; Hirobe, M. J. Chem. Soc., Perkin Trans. 1 1994, 1817.

(8) Tiehm, A. Appl. Environ. Microbiol. 1994, 60, 258.

(9) Borole, A. P.; Cheng, C. L.; Davison, B. H. Biotechnol. Prog. 2004, $20,1251$.

(10) Vazquez-Duhalt, R. J. Mol. Catal. B: Enzymol. 1999, 7, 241.

(11) Garcia-Arellano, H.; Valderrama, B.; Saab-Rincon, G.; VazquezDuhalt, R. Bioconjugate Chem. 2002, 13, 1336.

(12) Torres, E.; Sandoval, J. V.; Rosell, F. I.; Mauk, A. G.; Vazquez-

Duhalt, R. Enzyme Microb. Technol. 1995, 17, 1014.

(13) Xu, W. S.; Zhou, H.; Regnier, F. E. Anal. Chem. 2003, 75, 1931.

(14) Matsui, M.; Kiyozumi, Y.; Yamamoto, T.; Mizushina, Y.; Mizukami, F.; Sakaguchi, K. Chem. Eur. J. 2001, 7, 1555

(15) Kumar, C. V.; McLendon, G. L. Chem. Mater. 1997, 9, 863.

(16) Carrado, K. A.; Macha, S. M.; Tiede, D. M. Chem. Mater. 2004 $16,2559$.

(17) Kresge, C. T.; Leonowicz, M. E.; Roth, W. J.; Vartuli, J. C.; Beck, J. S. Nature 1992, 359, 710.

(18) Zhao, D.; Huo, Q.; Feng, J.; Chmelka, B. F.; Stucky, G. D. J. Am. Chem. Soc. 1998, 120, 6024.

(19) (a) Chong, A. S. M.; Zhao, X. S. Catal. Today 2004, 293. (b) Jing, H.; Li, X. F.; Evans, D. G.; Duan, X.; Li, C. Y. J. Mol. Catal. B: Enzymol. 2000, 11, 45. (c) Lei, C. H.; Shin, Y. S.; Liu, J.; Ackerman, E. J. J. Am. Chem. Soc. 2002, 124, 11242. (d) Fadnavis, N. W.; Bhaskar, V.; Kantam, M. L.; Choudary, B. M. Biotechnol. Prog. 2003, 19, 346. (e) Dumitriu, E.; Secundo, F.; Patarin, J.; Fechete, L. J. Mol. Catal. B: Enzymol. 2003, 22, 119. (f) Han, Y. J.; Watson, J. T.; Stucky, G. D.; Butler, A. J. Mol. Catal. B: Enzymol. 2002, 17, 1. (g) Yiu, H. H. P.; Wright, P. A.; Botting, N. P. Microporous Mesoporous Mater. 2001, 44, 763. (h) Xu, X.; Tian, B. Z.; Kong, J. L.; Zhang, S.; Liu, B. H.; Zhao, D. Y. Adv. Mater. 2003, 15 1932. (i) Wang, Y.; Caruso, F. Chem. Mater. 2005, 17, 953.

(20) Lee, C. H.; Wong, S. T.; Lin, T. S.; Mou, C. Y. J. Phys. Chem. B. $\mathbf{2 0 0 5}, 109,775$

(21) Washmon, L.; Jimenez, V. L.; Balkus, K. J. J. Mol. Catal. B: Enzymol. 2000, 10, 453.

(22) Zhao, J. W.; Gao, F.; Fu, Y. L.; Jin, W.; Yang, P. Y.; Zhao, D. Y. Chem. Commun. 2002, 752.

(23) (a) Gimon-Kinsel, M. E.; Jimenez, V. L.; Washmon, L.; Balkus, K. J. Stud. Surf. Sci. Catal. 1998, 117, 373. (b) Diaz, J. F.; Balkus, K. J. J. Mol. Catal. B: Enzymol. 1996, 2, 115
(24) (a) Deere, J.; Magner, E.; Wall, J. G.; Hodnett, B. K. Chem Commun. 2001, 465. (b) Deere, J.; Magner, E.; Wall, J. G.; Hodnett, B. K. J. Phys. Chem. B 2002, 106, 7340. (c) Deere, J.; Magner, E.; Wall, J. G.; Hodnett, B. K. Catal. Lett. 2003, 85, 19.

(25) (a) Takahashi, H.; Li, B.; Sasaki, T.; Miyazaki, C.; Kajino, T.; Inagaki, S. Microporous Mesoporous Mater. 2001, 44-45, 755. (b) Takahashi, H.; Li, B.; Sasaki, T.; Miyazaki, C.; Kajino, T.; Inagaki, S. Chem. Mater. 2000, 12, 3301 .

(26) Vinu, A.; Murugesan, V.; Tangermann, O.; Hartmann, M. Chem Mater. 2004, 16, 3056.

(27) Vinu, A.; Streb, C.; Murugesan, V.; Hartmann, M. J. Phys. Chem. B 2003, 107, 8297 .

(28) Han, Y. J.; Stucky, G. D.; Butler, A. J. Am. Chem. Soc. 1999, 121, 9897.

(29) Yiu, H. H. P.; Botting, C. H.; Botting, N. P.; Wright, P. A. Phys. Chem. Chem. Phys. 2001, 3, 2983.

(30) Yiu, H. H. P.; Wright, P. A.; Botting, N. P. J. Mol. Catal. B: Enzymol. 2001, 15, 81.

(31) (a) Shih, P. C.; Lin, H. P.; Mou, C. Y. Stud. Surf. Sci. Catal. 2003 , 146, 557. (b) Shih, P. C.; Wang, J. H.; Mou, C. Y. Catal. Today 2004, 93, 365.

(32) Han, Y.; Wu, S.; Sun, Y.; Li, D.; Xiao, F. S.; Liu, J.; Zhang, X. Chem. Mater. 2002, 14, 1144.

(33) (a) Cheng, Y. Y.; Chang, H. C.; Hoops, G.; Su, M. C. J. Am. Chem Soc. 2004, 126, 10828. (b) Smith, H. T.; Millett, F. Biochemistry 1980, 19 1117.

(34) Rodriguez-Lopez, J. N.; Lowe, D. J.; Hernandez-Ruiz, J.; Hiner, A. N. P.; Garcia-Canovas, F.; Thorneley, R. N. F. J. Am. Chem. Soc. 2001, 123,11838 .

(35) The computer simulations were performed using the WinSim program of the NIEHS public ESR software package. It is downloadable from the Internet (http://EPR.niehs.nih.gov).

(36) Barr, D. P.; Mason, R. P. J. Biol. Chem. 1995, 270, 12709.

(37) Chen, Y. R.; Mason, R. P. Biochem. J. 2002, 365, 461.

(38) Fan, J.; Yu, C. Z.; Gao, T.; Lei, J.; Tian, B. Z.; Wang, L. M.; Luo, Q.; Tu, B.; Zhou, W. Z.; Zhao, D. Y. Angew. Chem., Int. Ed. 2003, 42, 3146.

(39) Huang, L. C.; Chang, H. C. Langmuir 2004, 20, 5879.

(40) Barr, D. P.; Gunther, R. M.; Deterding, L. J.; Tomer, K. B.; Mason, R. P. J. Biol. Chem. 1996, 271, 15498.

(41) Itoh, T.; Yano, K.; Kajino, T.; Itoh, S.; Shibata, Y.; Mino, H. Miyamoto, R.; Inada, Y.; Iwai, S.; Fukushima, Y. J. Phys. Chem. B 2004, 108,13683 